\title{
Autism Tutor - An E-Parenting Tool
}

\author{
Pirani Zainab \\ Computer Engineering \\ Department \\ M.H.Saboo Siddik \\ College of Engineering
}

\author{
Salman Khan \\ Computer Engineering \\ Department \\ M.H.Saboo Siddik \\ College of Engineering
}

\author{
Rachana Khorjuwekar \\ Computer Engineering \\ Department \\ M.H.Saboo Siddik \\ College of Engineering
}

\author{
Azhar Memon \\ Computer Engineering Department \\ M.H.Saboo Siddik \\ College of Engineering
}

\begin{abstract}
Autism Tutor-"An eParenting Tool" is an application designed for android phones. The major aim of the application is to support the children suffering from Autism Spectrum Disorder(ASD).The android application also focuses on helping the parents and caretakers to deal with the problems that they while upbringing their autistic child. Through our application we try to provide knowledge to the caretakers and the parents about the stereotypical behavior of the child suffering from the disorder. We also make a point to tackle with the situations. The application will also take efforts to make sure that the autistic child is well groomed in the fields of communication and learning skills. The application makes use of audio video teaching tools with other advanced educational software's.
\end{abstract}

\section{General Terms}

Stereotypical behaviors, autistic, Social challenges.

\section{Keywords}

Android application, ASD, caretakers.

\section{INTRODUCTION}

\subsection{What is Autism Spectrum Disorder}

\section{(ASD)?}

Autism Spectrum Disorder or autism is a bunch of multiple complex disorders of brain development. Autism is also defined as being farthest alone from the very start of life and careful unyielding for wanting the preservation of equality [1]

Autism spectrum disorder is a moderate directed change of the brain. It is a follow on of the nervous system altering the standard brain that a normal child officiates with. Autism confuses the social life of an autistic child. The easily discovered signals and changes of an autistic child comes forth in the age of two to six years [2]. A person or a child suffering from autism always prefers to stick to a set of behavior and resist major or minor changes to daily activities.

\subsection{Symptoms of Autism spectrum \\ Disorder}

The basic symptoms shown by the child in the early stages of autism are:

- Doesn't give a direct eye contact.

- Doesn't respond to smiles.
- Doesn't respond when his or her name is called out.

- Doesn't follow objects visually.

- Doesn't point out or wave a goodbye or use any other gestures to communication.

- Doesn't make noise to give your attention.

- Doesn't initiate or react to cuddling.

- Doesn't easily play with others.

- Doesn't share interests or enjoyment with others.

- Doesn't ask or request for help when needed.

This abnormality is about 4 times less superior in females than in males. One percent of the total world population suffer from autism. It is appraised in USA that every year 68 autistic children are given birth. The total number of cases of Autism Spectrum Disorder is likely to be $1.5 \%$ and a while ago estimation of undetermined cases rises up to $2 \%$ [3].

People suffering from autism face problems in their day to day life. Every individual in autism is unique with unique needs and abilities hence it is important to keep in mind that they will experience or face the problems and issues in a unique way or may not face them at all.

\subsection{Problems faced by an autistic child}

Every child of autism has problems at least to some degree in the following three areas:

\subsubsection{Verbal and non verbal communication}

\subsubsection{Babbling}

It is a stage in the development of the child in which an i8nfant performs uttering articulate sounds, but not yet producing any recognizable words.

\subsubsection{Pica}

Pica is a tendency to eat things that are not food. Eating nonfood items is a normal part of development between the ages of 18 and 24 months

\subsubsection{Relating to others and the world around them}

\subsubsection{Flexible thinking and behaving}

Some people may think that they may be a better person being more alert of the difficulties being faced by others and are always ready to help others in their difficult times [4]. 


\subsection{Preface to Autism Tutor - "An eParenting Tool"}

Autism Tutor is designed to help the children of autism and deal with the communication, social and learning problems that they face on daily basis. The application also provides games and quiz to the children which can help them for their faster brain development. As the application also promises to help and support the parents and caretakers in upbringing the child. It also provides them with an log option in order to maintain the progress of the child.

The major objectives of the application are to make use of audio-video methods to make learning simple for the child.

- To create awareness among parents and caretakers about the stereotypical behavior of the child.

- Using technologies that will support the child as well as the parents for easy growth and development.

\section{LITERATURE SURVEY}

For the past few years there are many modes of technologies emerging in the electronic world to support an autistic child. These technologies have aimed to improve the quality of life of the people having various brain developmental disabilities. However, the attention of these technologies is limited in the field of autism. The technologies that are available for autistic children concentrate in enhancing the expressive communication skills, social interaction skills, attention skills, motivation skills, organization skills, academics skills, self help skills, overall independent daily functioning skill.

Before developing the application we have studied and successfully analyzed the following technologies:

\section{- MOSOCO}

- My Socious

- Smartphone Based applications

\subsection{MOSOCO [5]}

Visual representation techniques are used to make understanding simpler for children. Mobile social compass (MOSOCO) is an Existing system which has made an attempt to use various usual representation methods so that recognition becomes easier for the child [5].

MOSOCO was designed to provide social training to the child successfully. It makes use of social stories and paper based visual supports for teaching the children with autism. It focuses on encouraging the students to practice a social skill in different real life social situations.

\subsection{My Socious [6]}

Overcoming the drawback of MOSOCO, My Socious was designed for i-phone, i-pad, i-pod,. It is designed for parents to help their child to improve his/her communication skill. Where MOSOCO was focusing on improving the social skills of the child. My Socious concentrates on polishing the communication skills of the autistic child. This app makes use of particular methods that are natural for teaching the child during its day to day activities. My Socious allows the parents and the caretakers to view the progress of their child in daily basis, weekly basis, monthly basis or yearly basis. The progress report helps the parent to reinforce desired behavior, modify the learning environment to improve the child's chances to succeed.

\subsection{Smartphone based Autism Social Alert System [7]}

Smartphone Based Autism Social Alert System (SASA) uses inexpensive sensors embedded within smartphones to study the behavior of the autistic children by recording and analyzing the data collected from the inexpensive sensors. SASA is capable of detecting the stereotypical behaviour of the child [7].By effective analysis of the above 3 systems and use of technologies the application aims to address the educational challenges and individualized needs of the user with autism and also make it simpler for the parents and guardians of such special child to deal with such special child.

After analyzing the three systems it is understood that, making use of audio-visual representation in Autism Tutor will be of great use to the autistic children. Visual system allows the child to understand the topic with the help of objects, photographs, realistic drawings, line drawings and written words. A visual system allows the child to easily learn and perform the academic activities.

Like visual representation audio has also proved to be of great use to the children in increasing their listening abilities. Audios help the children to learn proper pronunciations of the words. It will help the child to communicate with others and improve his/her communication skill and increase his/her social life. Making use of effective technology helps the child to obtain a more affordable and higher quality education.

\section{PROPOSED SYSTEM}

Autism tutor is an application designed for teaching the children by using audio-visual methods. Audio visual methods are used for easy image recognition process. There are various texts and images made available for the child to grasp the academics easily. Along with the images the application also provides sound (audio) effect so that the child can learn the correct pronunciations. Sounds are also used to give a real effect to make the child experience a real learning environment. The major priority of the application is to help the parents and the caretakers to breed their children in a correct way.

By effective use of technologies the application aims to address the educational challenges and individualized needs of the user with autism and also makes it simpler for the parents and guardians of such special child to deal with such special children.

Autism Tutor is an android application which works as an elearning application designed for educating children of autism in an inclusive classroom. The application can be used by users having Smartphone's having android first by signing up or logging in. The user can sign up providing user information .The application further provides four categories to the user: social skills section, academic section, gaming zone and logs. The user can select any of the categories of his/her choice and perform the related activities.

The first category social skills section allows the user to perform tasks such as image recognition and also understand value education through visual methods. Human feelings and emotions are taught to the user by providing emoticons, appropriate text along with the emotions and an audio effect. The academic section covers the course syllabus and general knowledge through text and images. The general knowledge will be classified into science, history, math and entertainment. Flashcards and quiz will be included in the gaming zone. The logs are the last category which is used for 
maintaining the performance of the user. The app keeps a track of the user's, weekly and monthly performance, grades, ratings and results.
The aim is to address the educational challenges and individualized needs of the user with autism and also make it simpler for the parents of such special child to deal with such special child.

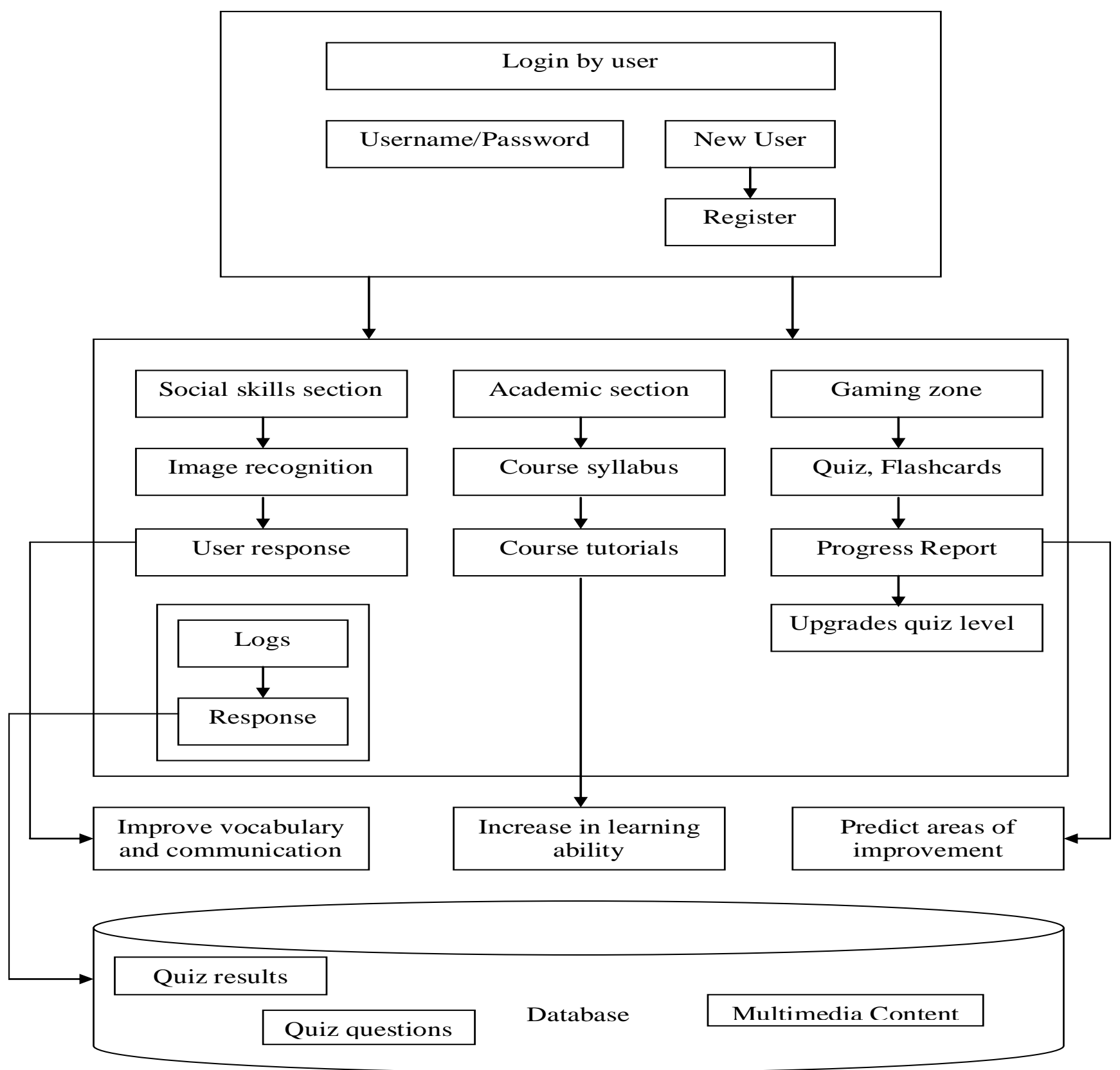

Fig 1: Block Diagram for Autism Tutor - "An eParenting Tool"

As the figure shows there are four categories provided to the user.

\subsection{Social Skills Section}

The first category social skill section where the user can perform a task called image recognition and also understand value education through visual methods. It shows moral stories to the child to learn human feelings. Emotions are taught to the user by providing emoticons, appropriate text along with the emotions and an audio effect.

\subsection{Academic Section}

The academic section covers the course syllabus and general knowledge through text and images. The general knowledge will be classified into English, Science, History, Math and Entertainment.

\subsection{Gaming Zone}

Flashcards and quiz will be included in the gaming zone.

\subsection{Logs}

The app keeps a track of the user's, weekly and monthly performance, grades, ratings and results. 


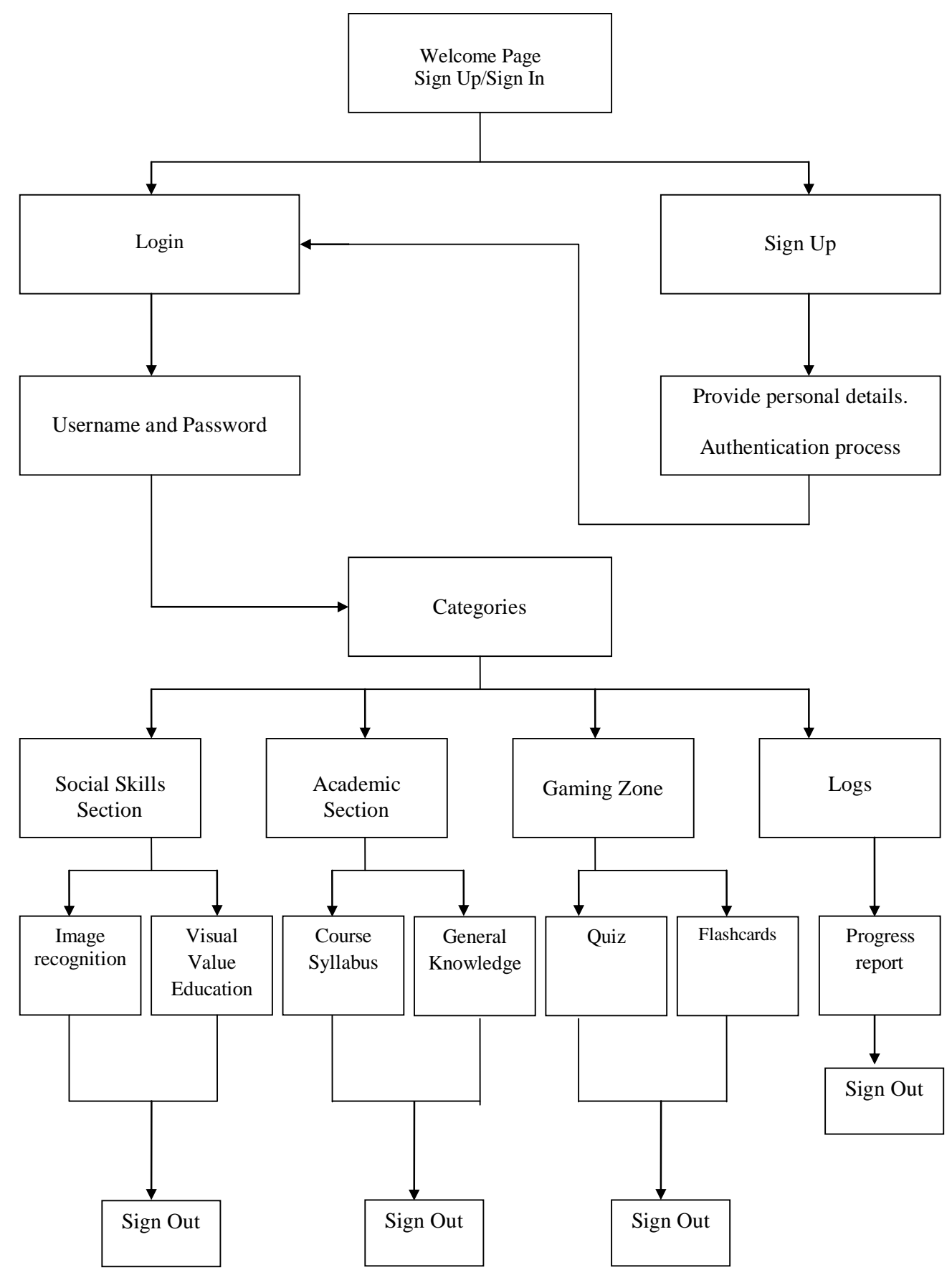

Fig 2: Flow of the System

\section{FLOW OF THE SYSTEM}

Autism Tutor caters to the needs of a special child and also aids the parents and the caretakers in upbringing a child with special needs. The main goal of this app is to enhance the expressing abilities of the autistic child which they lack as compared to a normal child. It focuses on acting as a catalyst in development of the child's brain. Since there is no specific medication of this condition, becoming one of them and treating them becomes an important aspect in helping such special children to develop. This app emphasizes on the role of parents in taking care of their child. It includes various activities which involves the parents along with the child, so that the child is not neglected by the parent. Since it is a smartphone based app it will be available to most of those who look upon technology as a way to solve problems. Being an android app it is assured to be user friendly and is

developed with the abilities of the child taken into consideration.

Autism tutor will allow the user to access by first logging in by entering its id and password. If the user is new to the system he will have to first sign in by providing its personal details such as name, age, gender, Id, and password. After logging in, the user can perform the following steps:

1. Select any One of the provided categories a) Social skills Section b) Academic Section c) Gaming Zone d) Logs. 


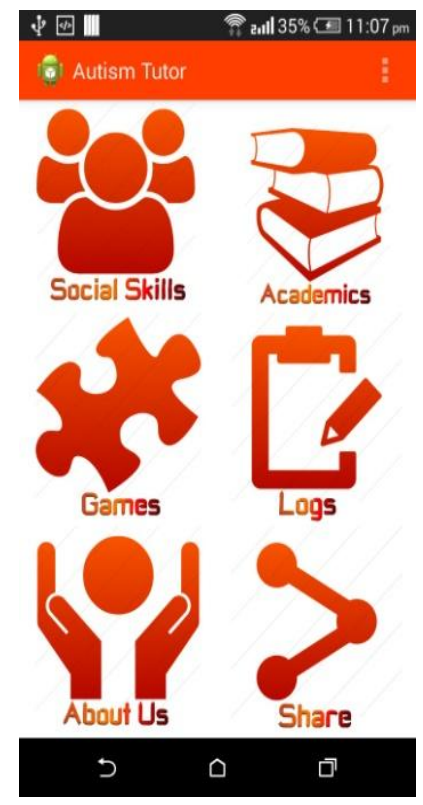

Screen 1: Main page

2. If the user selects the first category social skills he is again given three options 1) Stories 2) Emotions 3) Recognize. By selecting any of the three options the user can perform tasks of his choice.

\subsection{Stories}

If the user selects stories he can learn new values of life such as bravery, cleverness, honesty, friendship, etc through various moral stories.

\subsection{Emoticons}

If the user selects emotions he can learn various facial expressions an reactions an understand the emotions through the sound effect provided.

\subsection{Recognize}

The third option allows the user to recognize things, people and objects.

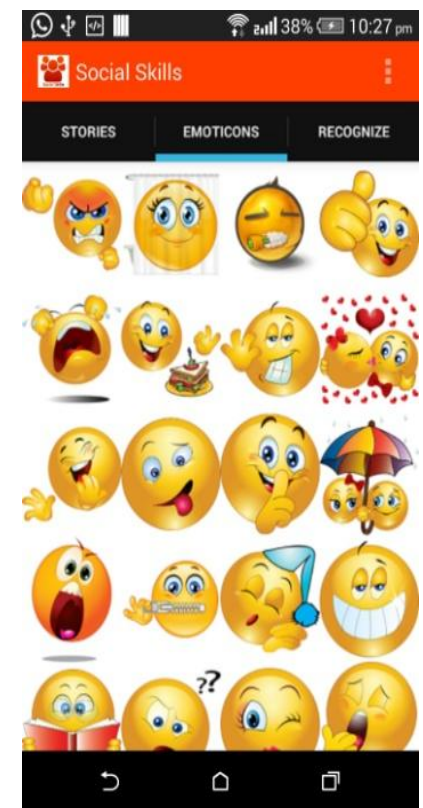

Screen 2: Social Skills
3. The user can now sign out or continue with other categories.

4. If the user selects the second category that is academics he is given options to learn months, days, fruits, vegetables, places and animals. By selecting any of the academic option the user can learn the syllabus in an exciting manner with images and sound effects.
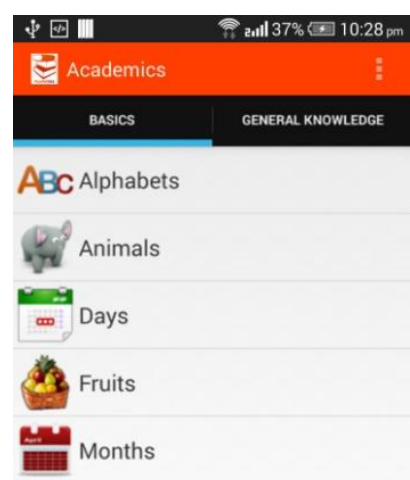

123 Numbers

\&.2 Vegetables

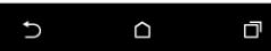

\section{Screen 3: Academics}

5. The user can sign out or continue with other categories.

6. If the user selects the gaming zone which is the third category he can play various games provided and also record his score.

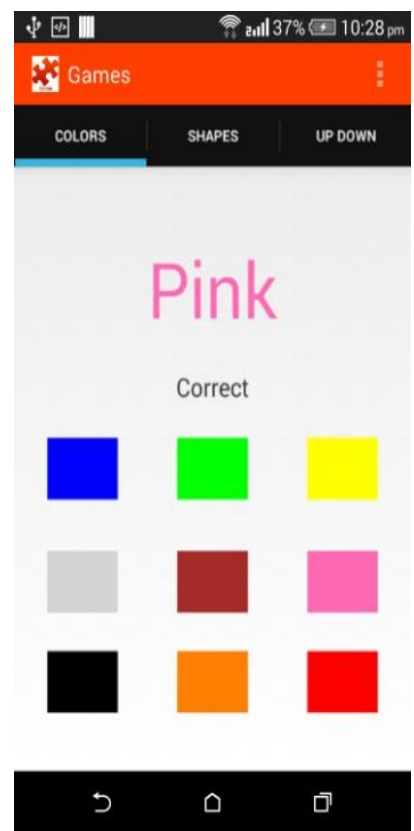

Screen 4: Gaming Zone

7. The user can sign out or continue with other categories.

8. The fourth and the last main categories is logs. Logs are specially designed for parents where the parents can maintain the daily, weekly, monthly or yearly progress of the child. 


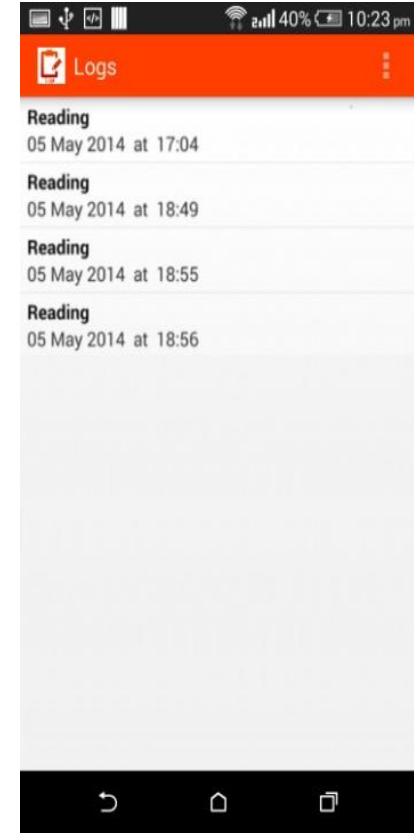

Screen 5: Logs

9. The user can sign out or continue with other categories.

10. Along with the four major categories the application also provides more two options to the user:

\subsection{About us}

The About us option gives an information to the user regarding the application and the developers of the application.

\begin{tabular}{l} 
Kids with autism often have difficulty \\
recognizing emotions and facial \\
expressions;this app created uses \\
moral stories and simple illustrations \\
to show what different feelings look \\
like with other additional academics \\
and games. The app also explains why \\
people may feel a certain way. \\
Autism Tutor is a comprehensive app \\
that could be used by people \\
diagnosed with autism,down \\
syndrome,other special need and \\
could also be used by their parents/ \\
guardians. This app is created as a \\
resource for anyone looking for an app \\
for people diagnosed with an autism \\
spectrum disorder or some other \\
mental disability. The app also has \\
links to video demonstrations to \\
improve the social skills of the one \\
$\quad 5 \quad \square \quad \square$ \\
\hline$\quad 0 \quad \square$
\end{tabular}

Screen 6: About us

10.2 Share

The share option allows the user to share the application to friends, families and relatives'. The application can be shared using Bluetooth, Gmail, face book, Mail, Google, Hangouts, Drop box.

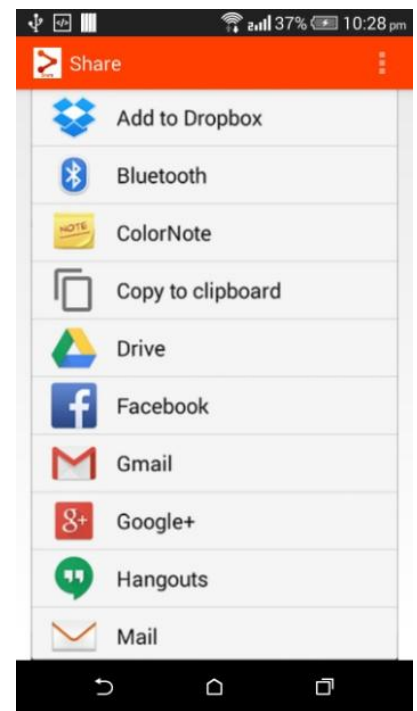

Screen 7: Share

11. The user can sign out or continue with other categories.

\section{RESULT ANALYSIS}

Table 1. Comparative Analysis

\begin{tabular}{|c|c|c|c|c|c|}
\hline \multirow{2}{*}{ System } & \multicolumn{5}{|c|}{ Quality Attributes } \\
\hline & Understandability & Useability & Simplicity & Secunty & Accessibility \\
\hline MOSOCO[] & $\checkmark$ & $\checkmark$ & $x$ & $x$ & $\checkmark$ \\
\hline $\begin{array}{l}\text { Smartphone } \\
\text { Based Autism } \\
\text { Social Alert } \\
\text { System [y] }\end{array}$ & $\checkmark$ & $\checkmark$ & $x$ & $x$ & $\checkmark$ \\
\hline $\begin{array}{c}\text { Proposed } \\
\text { System }\end{array}$ & $\checkmark$ & $\checkmark$ & $\checkmark$ & $\checkmark$ & $\checkmark$ \\
\hline
\end{tabular}

\section{CONCLUSION}

Due to balanced co-ordination among the team members, we have been successful in designing, planning and documenting the application, Autism Tutor - "An eParenting Tool". By acutely studying the symptoms of Autism, the problems faced by an autistic child and the difficulties faced by the parents and the caretakers, we have developed an application that tries to solve problems faced by the child and their parents. By scrutinizing the key features and functions of the existing applications MOSOCO, My Socius and Smartphone based Autism System. The application is developed with an aim to enhance the communication skills, social skills, of the child. It also focuses the grasping power of the child by using multimedia technologies and advanced educational software's. It also assures to help the parents and the caretakers to deal with the problems in raising an autistic child. Fortifying the child, parents and caretakers is our priority. In future we plan to sell books and cd's via the app having personal experiences of parents on how do they up bring a child with autism which will help the parents to deal with more real life experiences. Creating forums will let the users communicate with other users and share useful information with each other. Allowing the child to perform video conferencing will also be our prior goal in future. "Fulfilling the child's needs is our utmost motive and goal". 


\section{ACKNOWLEDGEMENTS}

We would like to thank the head of the computer department Z.A.Usmani for providing us this opportunity, we are grateful to our project guide Er. Zainab Pirani for her guidance and support. we would also like to mention our gratitude to the lab assistant Anwar sir to provide us with the required equipments

\section{REFERENCES}

[1] Zimmerman A. W (October,2008): Autism: Current theories and evidence. Humana Press, To-towa, NJ.

[2] http://www.autismspeaks.org

[3] Baron-Cohen S., Scott F., Allison C., Williams J,Bolton P., Matthews F., Bray-ne C(August,2009): Prevalence of autism-spectrum conditions. UK school-based population Study The British Journal of Psychiatry.

[4] Md. Monjurul Islam, Md. Abdullah Bin Amin \& Priyam Biswas (2013) : Increasing Speech Ability of the Autistic Children by an Interactive Computer Game.

[5] Lizbeth Escobedo, David H. Nguyen, LouAnne Boyd, Sen H. Hirano, Alejandro Rangel, Daniel García-Rosas, Monica Tentori, Gillian R. Hayes(May,2012) : MOSOCO (A Mobile Assistive Tool to Support Children with Autism Practicing Social Skills in Real-Life Situations)

[6] Evelyn Bartlett, Craig Lutz, Roger Bartlett (2012): My Socius.

[7] M. Chuah, M. DiBlasio(June,2012) : Smartphone Based Autism Social Alert System CSE Department Lehigh University Bethlehem, PA, USA. 